\title{
Tracheostomy in Children: Experience of a Tertiary Pediatric Intensive Care Unit
}

\section{Muhterem Duyu}

Department of Child Health and Diseases, Istanbul Medeniyet University, Goztepe Training and Research Hospital, Pediatric Intensive Care Unit, Istanbul, Turkey

\begin{abstract}
Introduction: In this study, we aimed to share the characteristics, results and experiences of the patients who underwent tracheostomy in our tertiary pediatric intensive care unit and who were admitted to home monitoring program after discharge. Methods: The medical records of patients who underwent tracheostomy at the Pediatric Intensive Care Unit of Medeniyet University, Göztepe Training and Research Hospital between May 2015 and June 2019 and followed up at home monitoring program after family education were retrospectively analyzed.

Results: A total of 47 patients 30 male (63.8\%) and 17 female (36.2\%) who met the criteria were included in the study. The median age on the day of tracheostomy was 33 months (range, 2-205), length of stay in the intensive care unit was median 66 days (range, 15-174), and the median follow-up after discharge was 845 days (range, 60-1520). The most common cause of tracheostomy was multiple trauma with 17 patients (36.2\%). Seventeen (36.2\%) of the patients were discharged with a home mechanical ventilator, while 30 (63.8\%) were discharged without a home mechanical ventilator. Female sex and home discharge with home ventilator support adversely affected survival ( $p=0.01, p=0.019)$.

Discussion and Conclusion: Tracheostomy and home mechanical ventilation is a good option for reducing the burden of chronic care patients in our country where the number of pediatric intensive care beds is limited. It is a cost-effective method that can be implemented easily and safely by families with different social and cultural levels with good education. Keywords: Children; home mechanical ventilation; tracheostomy.
\end{abstract}

$\mathrm{T}$ racheostomy is an important treatment method that enables children who need chronic mechanical ventilator support to speed up children's discharge to home who can be cared for at home at an earlier stage. With the introduction and development of home-type mechanical ventilators (HMVs) about 30 years ago, positive improvements have been achieved in the care and survival of pediatric patients with complex problems ${ }^{[1]}$. In addition to the increase in the number of children followed up at home with tracheostomy and mechanical ventilator support, the development of ventilator models and modes has also accelerated over time ${ }^{[2,3]}$.

The main indication for tracheostomy in the pediatric age group is the need for chronic respiratory support. Another common indication is upper airway obstruction, such as laryngotracheal anomaly and subglottic stenosis ${ }^{[4,5]}$. Advantages of opening a tracheostomy include better patient comfort, reduced need for sedation, reduced respiratory labor, faster separation from a mechanical ventilator, reduced risk of ventilator-associated pneumonia, reduced len-

Correspondence (İletişim): Muhterem Duyu, M.D. Medeniyet Universitesi Goztepe Egitim ve Arastirma Hastanesi Cocuk Yogun Bakim Unitesi Istanbul, Turkey

Phone (Telefon): +90 5556745661 E-mail (E-posta): drmuhteremduyu@gmail.com

Submitted Date (Başvuru Tarihi): 29.07.2019 Accepted Date (Kabul Tarihi): 05.08.2019

Copyright 2019 Haydarpaşa Numune Medical Journal

OPEN ACCESS This is an open access article under the CC BY-NC license (http://creativecommons.org/licenses/by-nc/4.0/)

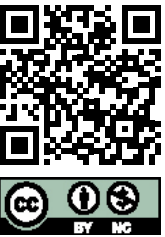


gth of stay in pediatric intensive care units, and improved oral hygiene ${ }^{[5,6]}$.

When the publications related to tracheostomy application in the pediatric age group are examined, there are different approaches to the issues, such as timing, indication, applied technique, home care in opening tracheostomy ${ }^{[5,6]}$. The prognosis of patients undergoing tracheostomy varies with age, associated comorbidity factors, patient anatomy, the experience level of the unit, the opening time of tracheostomy and the technique used $[4,6,7]$. The increase in the number of patients monitored with home-type mechanical ventilator and tracheostomy support allowed us to evaluate the long-term results after discharge from the intensive care unit. Various studies have been conducted on patients in the home monitoring program requiring chronic respiratory support due to muscle or lung disease and their long-term outcomes ${ }^{[8-10]}$. There are several studies showing that children connected to the chronic respiratory device can be managed successfully with a good home monitoring program and follow-up method despite higher mortality rates in diseases with poor prognosis $[10,11]$. The aims of home monitoring of he children who were followed up by tracheostomy were to extend their life span, to prevent the occurrence of additional disease(s), to accelerate the process of physical and psychological recovery, to optimize the quality of life of children and families and to reduce costs ${ }^{[12]}$.

In parallel with the increase in the number of patients in the pediatric age group, especially in home mechanical ventilation support, larger-scale analyzes and studies have begun to be conducted. However, in Turkey, only a limited number of studies have been performed with a limited series of patients. In this study, clinical features, long-term follow-up and factors affecting the prognosis of patients discharged home with tracheostomy support from our pediatric intensive care unit were evaluated retrospectively.

\section{Materials and Methods}

In this study, patients between one month and 18 years who underwent tracheostomy in Medeniyet University, Göztepe Training and Research Hospital, Pediatric Intensive Care Unit between May 2015 and June 2019 were evaluated retrospectively. Medeniyet University Göztepe Training and Research Hospital Ethics Committee approval was obtained (Decision No: 2019/0256) for this study. Age, sex, tracheostomy opening day, number of intensive care hospitalization days, underlying disease (s), follow-up period at home, HMV support status, parental education status, number of people living at home, the region of residence and survival data were recorded. Patients who underwent tracheostomy at the external center who died before being discharged home after tracheostomy was opened and patients who could not be followed up after discharge were excluded from this study.

Training for the family members who will provide home care was provided by senior trained nurses in compliance with the "Intensive Care of Child at Home, Family Care at Home" training guide and form organized by our unit for standardization of education. At least two family members of each patient were included in the home care program. In training forms competency of the participants was provided concerning the issues, including aspiration, replacement of the tracheostomy cannula, nutrition education (oral/nasogastric/gastrostomy), approach to emergencies (tracheostomy blockage or displacement, equipment failure, oxygen saturation decrease, heart rate weakening), and use of home-type equipment (home-type mechanical ventilator) device, oxygen concentrator, rechargeable aspirator, pulse oximeter).

The patients were transferred home by an ambulance, accompanied by a doctor. The phone numbers of the intensive care unit/physician were given in case the patients/ caregivers could get contact with if the patients might encounter any problem at home. The discharged patients were called for periodic controls according to the underlying disease and the patient's clinic.

\section{Statistical Analysis}

Statistical analysis of the data was performed by NCSS (Number Cruncher Statistical System) 2007 Statistical Software (Utah, USA). In addition to descriptive statistical methods (frequency and percentage distributions, median, interquartile range), independent t-test was used for comparison of pairs of normal distribution variables, MannWhitney $\mathrm{U}$ test for comparison of pairs without normal distribution, and chi-square test for comparison of qualitative data were used. $\mathrm{P}<0.05$ was considered statistically significant for all results.

\section{Results}

Between May 2015 and June 2019, 1642 patients were admitted to the pediatric intensive care unit. 864 patients (52.6\%) were monitored by intubation and mechanical ventilator support. Of 864 patients, 55 (6.4\%) underwent a tracheostomy. Six patients were excluded from this study after discharge and two died before discharge. Thus, 47 patients were included in the study. Thirty (63.8\%) patients were 
male and 17 (36.2\%) of them were female. The median age of the patients at the time of opening of tracheostomy was 33 months (range, 2-205). Multiple trauma ranked first in the distribution of the underlying diagnoses that required tracheostomy (36.2\%), followed by neuromuscular disease was $23.4 \%(n=11)$, chronic lung disease $12.8 \%(n=6)$, congenital cardiopathy $12.8 \%(n=6)$, metabolic disease $6.4 \%$ $(n=3)$, hypoxic-ischemic encephalopathy $4.2 \%(n) 2)$ and airway anomaly $4.2 \%(n=2)$ in decreasing order of frequency (Table 1)

The median time to the insertion of the tracheostomy tube was 14 days (range, 5-55), and the median duration of ICU stay was 66 days (range, 15-174). While $36.2 \%(n=17)$ of the patients with tracheostomy were discharged home with HMV support, and $63.8 \%(n=30)$ of them were followed up without HMV support. The median follow-up period after discharge was 845 days (range, 60-1520). The tracheostomies of $23.4 \%(n=11)$ of the patients who were included in the home monitoring program with a tracheostomy were closed (Table 1). The detailed distribution of the diagnoses of the patients undergoing tracheostomy is shown in Table 2 .

Table 1. Characteristic features of the patients included in the study and distribution of their diagnoses

\begin{tabular}{|c|c|}
\hline Variables & Values \\
\hline \multicolumn{2}{|l|}{ Gender } \\
\hline Female, n, (\%) & $17(36.2)$ \\
\hline Male, $n,(\%)$ & $30(63.8)$ \\
\hline Age at tracheostomy, median, (min-max), (mos) & $33(2-205)$ \\
\hline \multicolumn{2}{|l|}{ Underlying disease $\mathrm{n},(\%)$} \\
\hline Multiple trauma & $17(36.2)$ \\
\hline Neuromuscular disease & $11(23.4)$ \\
\hline Chronic lung disease & $6(12.8)$ \\
\hline Conjenital cardiyomyopatihy & $6(12.8)$ \\
\hline Metabolic disease & $3(6.4)$ \\
\hline Hipoxic iscjhemic encephalopathy encephalopathy & $2(4.2)$ \\
\hline Airway abnormality & $2(4.2)$ \\
\hline Tracheostomy opening day, median, (min-max), (day) & $14(5-55)$ \\
\hline Intensive care unit stay, median, (min-max), (day) & $66(15-174)$ \\
\hline Type of discharge home, $n,(\%)$ & $17(36.2)$ \\
\hline $\begin{array}{l}\text { With home type mechanical } \\
\text { ventilator support, } \mathrm{n},(\%)\end{array}$ & $30(63.8)$ \\
\hline $\begin{array}{l}\text { Without home type mechanical } \\
\text { ventilator support, } n,(\%)\end{array}$ & $845(60-1520)$ \\
\hline $\begin{array}{l}\text { Follow-up period after discharge, } \\
\text { median, (min-max), (day) }\end{array}$ & $11(-23.4)$ \\
\hline Closure of tracheostomy ${ }^{*}, \mathrm{n},(\%)$ & \\
\hline
\end{tabular}

*: Tracheostomy closure procedures during follow-up period after discharge.
Table 2. Detailed description of diagnoses of the patients in whom tracheostomies were performed

\begin{tabular}{lc}
\hline Distribution of diseases, $\mathbf{n , ~ ( \% )}$ & Diagnoses (n) \\
\hline Multiple traumas, & Severe traumatic brain damage (16) \\
$17(36.2 \%)$ & Spinal injury (1) \\
Neuromuscular disease, & Central nervous system infection (3) \\
$11(23.4 \%)$ & Central nervous system tumor (2) \\
& Cerebral palsy (2) \\
& Hydroscephalus (1) \\
& Polyneuropathy (1) \\
& SSPE (1) \\
Chronic Lung disease & Transverse myelitis (1) \\
(12.8\%) & Bronchiolitis obliterans obliterans (3) \\
Congenital cardiomyopathy & Esophageal atresia (3) \\
6 (12.8\%) & Hipoplastic left heart (3) \\
& VSD, pulmonary hypertension (1) \\
Endocardial cushion defect (1) & AVSD (1) \\
M (\%6.4) & Foreign body aspiration (1) \\
Hypoxic ischemic & Subglottic stenosis (2) \\
encephalopathy, 2 (4.2\%) & Undefined neurometabolic disease (2) \\
Airway abnormality, 2 (\%4.2) & Organic acidemia (1) \\
\hline
\end{tabular}

SSPE: Subacute sclerosing panencephalitis, VSD: Ventricular septal defect, AVSD: Atrioventricular septal defect.

The relationship between gender, age, type of home discharge (HMV-supported/non-HMV-supported), underlying disease, parental education level, the region of residence, the number of individuals living at home, and their impacts on survival was evaluated (Table 3). The mortality rate was $23.3 \%(n=4)$ in boys and $41.2 \%(n=7)$ in girls $(p=0.01)$. The median age was 37.5 months in the surviving cases and 27 months in the deceased cases. There was no significant relationship between age and survival $(p=0.213)$. Mortality $(33.3 \%, \mathrm{n}=6)$ was significantly higher in patients who were discharged with HMV support than patients who were discharged without HMV support $(16.7 \%, n=5)(p=0.019)$. There was no significant relationship between the underlying disease and survival $(p=0.430)$.

There was no significant difference between parental education levels and survival $(p=0.219,0.093)$. Mortality was $25 \%(n=1)$ in rural areas and $23.2 \%(n=10)$ in the city center. No significant difference was found between the region of residence and mortality $(p=0.211)$. Mortality was found to be $25.0 \%(n=2)$ in the group with $\leq$ three individuals living in the household, and $23.1 \%(n=9)$ in the group $\geq$ four individuals in the household without any significant correlation with survival ( $p=0.92$ ) (Table 3 ). 
Table 3. The impact of characteristic features, and familial factors on survival

\begin{tabular}{|c|c|c|c|}
\hline Variable & Survived $(n=36)$ & Death $(n=11)$ & $\mathbf{p}$ \\
\hline \multicolumn{4}{|l|}{ Gender n, (\%) } \\
\hline Male & $26(86.7)$ & $4(23.3)$ & 0.01 \\
\hline Female & $10(58.8)$ & $7(41.2)$ & \\
\hline Age (year), median & 37.5 & 27 & 0.213 \\
\hline \multicolumn{4}{|l|}{ Type of home discharge, $n,(\%)$} \\
\hline With home type ventilator support & $11(64.7)$ & $6(33.3)$ & 0.019 \\
\hline Without home type ventilator support & $25(83.3)$ & $5(16.7)$ & \\
\hline Underlying disease $\mathrm{n},(\%)$ & & & 0.430 \\
\hline Multiple traumas & $16(94.1)$ & $1(5.9)$ & \\
\hline Neuromuscular disease & $8(72.7)$ & $3(27.3)$ & \\
\hline Chronic lung disease & $3(50.0)$ & $3(50.0)$ & \\
\hline Congenital cardiomyopathy & $4(66.7)$ & $2(33.3)$ & \\
\hline Metabolic disease & $3(100)$ & $0(0)$ & \\
\hline Hipoxic ischemic encephalopathy & $1(50.0)$ & $1(50.0)$ & \\
\hline Airway abnormality & $1(50.0)$ & $1(50.0)$ & \\
\hline Educational level of the mother, $\mathrm{n}(\%)$ & & & 0.219 \\
\hline Primary & $29(72.5)$ & $11(27.5)$ & \\
\hline High school & $6(100)$ & $0(0.0)$ & \\
\hline University & $1(100)$ & $0(0.0)$ & \\
\hline Educational level of the father, $n,(\%)$ & & & 0.093 \\
\hline Primary & $23(52.3)$ & $11(47.7)$ & \\
\hline High school & $11(100)$ & $0(0.0)$ & \\
\hline University & $2(100)$ & $0(0.0)$ & \\
\hline \multicolumn{4}{|l|}{ The living place, $n,(\%)$} \\
\hline Rural & $3(75.0)$ & $1(25.0)$ & 0.211 \\
\hline City center & $33(76.8)$ & $10(23.2)$ & \\
\hline Number of household members & & & 0.92 \\
\hline$\leq 3$ & $6(75.0)$ & $2(25.0)$ & \\
\hline$\geq 4$ & $30(76.9)$ & $9(23.1)$ & \\
\hline
\end{tabular}

\section{Discussion}

Mechanical ventilation at home plays an important role in the treatment of patients with chronic respiratory failure [13]. Parallel to the development of home care services, mechanical ventilation at home has become more applicable over the years. In the UK, Wallis et al., ${ }^{[14]}$ indicated in their study that 36 patients had received mechanical ventilation at home, it was reported that by 2008 , this number reached to 933 . In a study conducted in a state in the United States, the prevalence of HMV was $6 / 100.000$, and when this ratio was adapted to the whole country, it was estimated that 4.100 children were followed up with a home mechanical ventilation system. In our country, the first study of HMV in the pediatric age group was performed by Öktem et al. ${ }^{[15]}$ in a series of 34 patients.

Neuromuscular diseases, traumatic brain injury, including spinal cord trauma, craniofacial congenital anomalies and chronic lung diseases are among the main indications of chronic respiratory support in the pediatric age group [13, ${ }^{16]}$. In the study of Pekcan et al., it was reported that neuromuscular diseases constituted $59.3 \%$ of tracheostomy patients followed with mechanical ventilator support at home. In our series, multiple trauma patients (36.2\%) and neuromuscular diseases (23.4\%) took the first two places. Since we are a multidisciplinary hospital and our unit is a tertiary intensive care unit, trauma patients are frequently treated in our hospital and constitute an important part of the inpatient population.

There are several studies on the timing of elective tracheostomy opening and related factors in pediatric patients $[17,18]$. Shorter incubation times as 13 days (range, 0-148) before tracheostomy were published in a study performed in the USA [17]. In our study, a similar result was obtained in terms of the opening time of tracheostomy (median: 14 days). In our study, the median length of stay in the inten- 
sive care unit was 66 days (range, 15-174). In another study longer length of stay in ICU (median: 32 days, range: 1-122 days) was reported ${ }^{[19]}$.

The duration of hospitalization is prolonged due to improper home conditions, difficulties in both obtaining appropriate equipment, and also in the standardization of family education, and an inadequate number of nurses trained in chronic ventilation ${ }^{[20]}$. According to our experience, we have had long hospitalizations due to difficulties in family education and difficulties and delays in the provision of appropriate equipment for home care.

Children with mechanical ventilator support at home may be separated from respiratory support, or their tracheostomies may be closed due to the improvement in underlying diseases, such as chronic lung disease, bronchopulmonary dysplasia, and accompanying aggravating factors. Tracheostomy closure rates vary between $17 \%$ and $78 \%$ in the literature. This wide range is due to the diversity of underlying indications and differences in medical problems associated with the patient ${ }^{[18,21,22]}$. In a study by Kamil et al. ${ }^{[19]}$ from Turkey tracheostomy was closed in 8 (12.6\%) of 63 patients who underwent tracheostomy.

In our study, tracheostomy was closed in 11 cases (23.4\%) after discharge. Cases who had closed tracheostomy before discharge were not included in our study. In the follow-up of the patients discharged with HMV, tracheostomy closure was found to be significantly lower than the group without support ( $p=0.011$ ). It has been reported that the long-term prognosis of patients undergoing HMV is closely related to the underlying disease. There are studies reporting that mortality rates in chronic neurological diseases are higher than other disease groups ${ }^{[13,23]}$. In their study, Kamit et al. ${ }^{[19]}$ have shown that the underlying disease and age do not affect mortality. In our study, no relationship was found between the underlying disease, age and mortality.

Although there was a significant relationship between female gender and mortality in our study, it should be remembered that our evaluation was based on a limited number of cases. In our study, it was shown that the presence of HMV support during discharge had a negative effect on mortality $(p=0.019)$. In this study, the relationship between family and social and cultural factors on mortality was also investigated. The education level of the parents, the rural-urban area of the region of residence, the number of individuals living at home had no effect on survival. Pekcan et al. from Turkey showed that the same factors were not effective on survival.

\section{Conclusion}

Mechanical ventilation at home is a good option for alleviating the burden of chronic care patients in our country, Turkey, where the number of pediatric intensive care beds is limited. Early tracheostomy is thought to allow the patient to be separated from mechanical ventilator support and discharged from the pediatric intensive care unit at an earlier stage. Apart from the factors associated with the patient, difficulties in obtaining appropriate equipment, deficiencies in educational health personnel, inadequacy in home care services, difficulties in family education, and barriers to patient discharge are the main obstacles to scheduling patient discharge. Despite all these deficiencies, there has been a significant increase in the number of tracheostomy patients at home in recent years. Our study showed that pediatric patients with a tracheostomy with or without HMV could be followed up safely and successfully at home. It is a cost-effective method that can be implemented easily and safely by families with different socio-cultural levels with good education.

Ethics Committee Approval: Medeniyet University Göztepe Training and Research Hospital Ethics Committee approval was obtained (Decision No: 2019/0256) for this study.

Peer-review: Externally peer-reviewed.

Conflict of Interest: None declared.

Financial Disclosure: The author declared that this study received no financial support.

\section{References}

1. Amirnovin R, Aghamohammadi S, Riley C, Woo MS, Del Castillo $S$. Analysis of a Pediatric Home Mechanical Ventilator Population. Respir Care 2018;63:558-64.

2. Ottonello G, Ferrari I, Pirroddi IM, Diana MC, Villa G, Nahum L, et al. Home mechanical ventilation in children: retrospective survey of a pediatric population. Pediatr Int 2007;49:801-5.

3. Graf JM, Montagnino BA, Hueckel R, McPherson ML. Pediatric tracheostomies: a recent experience from oneacademic center. Pediatr Crit Care Med 2008;9:96-100.

4. Berry JG, Graham RJ, Roberson DW, Rhein L, Graham DA, Zhou $J$, et al. Patient characteristics associated with in-hospital mortality in children following tracheotomy. Arch Dis Child 2010;95:703-10.

5. Kremer B, Botos-Kremer Al, Eckel HE, Schlöndorff G. Indications, complications, and surgical techniques for pediatric tracheostomies--an update. J Pediatr Surg 2002;37:1556-62.

6. Durbin CG Jr. Tracheostomy: why, when, and how? Respir Care 2010;55:1056-68.

7. Berry JG, Graham DA, Graham RJ, Zhou J, Putney HL, O'Brien $\mathrm{JE}$, et al. Predictors of clinical outcomes and hospital resource 
use of children after tracheotomy. Pediatrics 2009;124:56372.

8. Sritippayawan S, Kun SS, Keens TG, Davidson Ward SL. Initiation of home mechanical ventilation in children with neuromuscular diseases. J Pediatr 2003;142:481-5.

9. Sakakihara Y, Yamanaka T, Kajii M, Kamoshita S. Long-term ventilator-assisted children in Japan: a national survey. Acta Paediatr Jpn 1996;38:137-42.

10. Amin R, Sayal P, Syed F, Chaves A, Moraes TJ, MacLusky I. Pediatric long-term home mechanical ventilation: twenty years of follow-up from one Canadian center. Pediatr Pulmonol 2014;49:816-24.

11. Canlas-Yamsuan M, Sanchez I, Kesselman M, Chernick V. Morbidity and mortality patterns of ventilator-dependent children in a home care program. Clin Pediatr (Phila) 1993;32:706-13.

12. Fraser J, Henrichsen T, Mok Q, Tasker RC. Prolonged mechanical ventilation as a consequence of acute illness. Arch Dis Child 1998;78:253-6.

13. Lloyd-Owen SJ, Donaldson GC, Ambrosino N, Escarabill J, Farre R, Fauroux $B$, et al. Patterns of home mechanical ventilation use in Europe: results from the Eurovent survey. Eur Respir J 2005;25:1025-31.

14. Wallis C, Paton JY, Beaton S, Jardine E. Children on long-term ventilatory support: 10 years of progress. Arch Dis Child 2011;96:998-1002.

15. Oktem S, Ersu R, Uyan ZS, Cakir E, Karakoc F, Karadag B, et al. Home ventilation for children with chronic respiratory failure in Istanbul. Respiration 2008;76:76-81.

16. Srinivasan S, Doty SM, White TR, Segura VH, Jansen MT, Davidson Ward SL, et al. Frequency, causes, and outcome of home ventilator failure. Chest 1998;114:1363-7.

17. Graf JM, Montagnino BA, Hueckel R, McPherson ML. Pediatric tracheostomies: a recent experience from one academic center. Pediatr Crit Care Med 2008;9:96-100.

18. Zia S, Arshad M, Nazir Z, Awan S. Pediatric tracheostomy: complications and role of home care in a developing country. Pediatr Surg Int 2010;26:269-73.

19. Can FK, Anıl AB, Anıl M, Gümüşsoy M, Çitlenbik H, Kandoğan T, et al. The outcomes of children with tracheostomy in a tertiary carepediatric intensive care unit in Turkey. Turk Pediatri Ars 2018;53:177-184.

20. Noyes J. Enabling young 'ventilator-dependent' people to express their views and experiences of their care in hospital. J Adv Nurs 2000;31:1206-15.

21. Serra A, Cocuzza S, Longo MR, Grillo C, Bonfiglio M, Pavone P. Tracheostomy in childhood: new causes for an old strategy. Eur Rev Med Pharmacol Sci 2012;16:1719-22.

22. Carron JD, Derkay CS, Strope GL, Nosonchuk JE, Darrow DH. Pediatric tracheotomies: changing indications and outcomes. Laryngoscope 2000;110:1099-104.

23. Tekerek NÜ, Dursun A, Akyıldız BN. Home Mechanical Ventilation in Children: Erciyes University Experience. J Turk Soc Intens Care 2017;15:28-33. 